\title{
Da Violência como Instrução ao (Des)afeto como Constrangimento: Acumulação Pulsional, Identidades Segmentadas e Clausuras do Comum em Casa Grande (Felipe Barbosa, 2014) e Que Horas Ela Volta (Anna Muylaert, 2015)
}

Rafael Tassi Teixeira

\section{Casa Grande (Felipe Barbosa, 2014) e Que Horas Ela Volta (Anna Muylaert, 2015)}

Os dois filmes brasileiros que se inserem no desenvolvimento dessas perspectivas (releituras da construção do pertencimento em novas (velhas) dialéticas das impossibilidades) do habitar na realidade cotidiana brasileira que geraram ampla discussão sobre as relações entre patrões e empregados nos últimos dois anos foram: Que Horas Ela Volta (Anna Muylaert, 2015) e Casa Grande (Felipe Barbosa, 2014).

Nessas duas "materialidades sensíveis" (Rancière, 2005), o pertencimento e a figuração dos corpos são pré-estabelecidos pelas geografias mudas, silenciosas, clandestinas, que determinam os lugares e os processos de encontro em recursos de encenação, como se as relações estivessem sempre premidas pelas incapacidades em superar os registros (o campo de força, os abismos antagônicos) que, mesmo aceitando as identidades, não conseguem perfurá-las no espaço da busca da simetrização em igualdades exercidas (sob diferenças disfarçadas). As estratégias de suspensão desse universo, tanto em Que Horas Ela Volta como Casa Grande, tem a ver, portanto, com o inequívoco da diferenciação: as posições sociais são dependentes das cortesias das relações, que são medidas pelos pactos de amparo afetivo, mas afetivo na frequência com que obedecem a uma dependência da alteridade usada preferencialmente para ser exibida ${ }^{1}$.

Os dois filmes parecem indicar a uma necessidade de ocultação frequente das relações de abuso e dominação, que, em um sentido de dependência relativa, pelo esforço do afeto em ser completado pela parcialidade do interesse, transfere as relações profissionais - para o campo das lógicas dos acordos tácitos da emocionalidade. Em Casa

\footnotetext{
${ }^{1}$ Essa exibição é possível porque a narrativa de Casa Grande e Que Horas ela Volta, aponta para a herança dos corpos dentro dos sistemas sociais sem redirecionamento das espectralidades vigentes. Em universos de totalização em que os sujeitos são discriminados pela predicabilidade da pessoa, os lugares são herdados sem margem ao equívoco da concepção de origem. Isso fica bastante expresso, por exemplo, em Que horas ela Volta, quando o personagem do patrão (Dr. Carlos, Lourenço Mutarelli), ao ser perguntado sobre como tinha dinheiro para viver na casa, responde que 'herdou o imóvel', revelando, assim, a natureza rígida das posições sociais pré-estabelecidas por seus amparos \deformações naturalistas.
} 
Grande e Que Horas Ela Volta a questão central é a ordem implícita do afeto como um espelho da ordem do desejo de ser (frequentar periodicamente) um outro que é exigido pela imersão.

A fixação dos corpos que são emulados sem as condições que os revelam explicam, como reflete (Dunker, 2015), sistemas de compensações onde a alternância de poder inexiste, apresentando-se como uma impossibilidade de lidar com a construção das historicidades correlatas e copresenças habitadas por uma relativização parcial, apenas.

No filme de Felipe Barbosa, o centro da narrativa é direcionado pelos olhos do rapaz (Jean, Thales Cavalcanti) um estudante de colégio tradicional no Rio de Janeiro que, no último ano do ensino médio, gravita entre a mansão em que os pais vivem (e clandestinamente tentam esconder que estão falidos) e o princípio do mundo da rua, dos limites 'extra-muro', que começam a aparecer quando desenha um universo de relações (a garota de outra realidade sócio-econômica que conhece no trajeto de ônibus, as atividades da cultura popular que começa a experimentar ao longo do filme, etc.) fora da apreensão diária da Casa Grande.

A narrativa permeia-se de pequenas evoluções estabelecidas a partir do acompanhamento da falência da estrutura econômica da família (mantida em segredo, negada até o último movimento) quando os pais de Jean, Hugo (Marcello Novaes) e Sônia (Suzana Pires) demitem o motorista que o leva diariamente à escola, e o garoto passa a sentir que as coisas não seguem seu padrão usual. A história abre-se às pequenas sobrevivências de um mundo, portanto, que é perfurado pela consideração das novas realidades observadas pelos olhos de Jean, ao ver-se obrigado a usar o transporte coletivo para se deslocar. A dinâmica do epicentro casa, esfacelando-se gradualmente, e com possibilidades de um mundo sem limites, abrem-se à compreensão crescente e as novas frustrações (Jean tem um discurso investido de inocência que se esvai ao ser comparado com a garota, [Bruna Amaya], que conhece em um ônibus e que começa a se interessar).

Nesse sentido, a ordem da convivência determinada pela incompreensão de horizontes díspares de partida e a diferença entre os mundos, são explorados pela tensão objetiva do filme, que cresce com a configuração dos diálogos e a saída ao universo, pelo rapaz, das relações humanas fora do espaço centralizado da casa². A queda dos pais como

\footnotetext{
${ }^{2} \mathrm{O}$ filme, da mesma forma que Que Horas ela Volta, trabalha com uma estilística discursivamente usual, com bom apoio de diálogos e interpretações cuidadosas, estabelecendo limites de câmera no plano tradicional com tempos poucos distentidos e espacialidade de quadros que aproveitam todo o recurso da imagem (há pouca ambivalência, nesses dois filmes, do uso possível do extra-campo em relação a duplicidade da imagem, centrando-se a proposta estética no desempenho da narrativa para atrair a atenção). Os esconderijos das imagens se desenvolvem, portanto, apenas na diegése, e o espaço-tempo, dos dois filmes, segue um alinhamento típico das linguagens dominantes dos últimos filmes do cinema brasileiro contemporâneo: captura de quadros com inserção dos corpos em dramaturgias bem amarradas, planos médios interiores, fotografia discreta e montagem 'invisível'.
} 
fiabilidade sócio-econômica e relato cultural (a dissecação bem-feita do filme dos ricos com linguagens autocentradas e laudatórias), da mesma forma que o questionamento dos discursos paternos emudecidos, por parte de Jean, passam a impor uma tensão gerada pela destoamento das concepções de existência: enquanto os pais se preocupam em manter as aparências e enganar-se mutuamente, Jean começa a namorar a menina mulata que estuda em escola pública e que rompe com seus padrões de mutismo social. A saída ao mundo é, admiravelmente, a perda da inocência que tem seu limite, na segunda metragem do filme, entre as expectativas frustradas por parte de Jean em relação ao descobrimento do amor e a atividade sexual ainda imatura, e os espaços de vazio abertos pela constatação maior: os pais não prepararam ao mundo porque o mundo era retido em um muro privado (a imagem dos olhos \rosto de Jean nos portões de ferro da casa, em uma cena do filme expõe graficamente essa anatomia).

Do mesmo modo, quando as certezas ao redor começam a ruírem e as falências desse imaginário revestido de grandes portões, jardins embelezados e piscina iluminada, o rapaz é tentativamente retirado, pelos pais superprotetores, das circunstâncias do cotidiano além muro. A fuga do universo da imagem, assim como o derramamento das potências paternas (Jean briga com o pai questionando-lhe a autoridade) não é outra que a necessidade de percorrer a afetividade real para além da experiência da discordância: Jean, que sempre fora, clandestinamente, ao quarto da empregada da família (Clarissa Pinheiro), busca as peças faltantes dessas 'sombras necessárias' descartadas, uma a uma, pela família em crise.

A experiência física e sexual precisa de acolhimento que, no caso do garoto, investe pela metáfora da afetividade conhecida: é através destes afetos aceitos, é através da surpresa da invisibilidade e do despreparo ao mundo que, em seu retraimento, Jean busca respostas dentro da condição do mundo nas mesmas margens da casa, ou de seu sistema central (cozinha, funcionalidade dos quartos marginais, admissão das reentrâncias como recuperação do vazio e da rudeza da casa). A queda dessa organização sensível e amplamente conhecida, mas sempre anulada pela espacialidade remota, terá consequências, como o filme espera e produz a partir de sua meia hora final, com a perda dos corpos concebidos como gravitação das existências, especialmente quando o menino aprende que não há outra saída a não ser sair ao mundo buscando suas margens (afetivas realmente).

Essa imagem irá durar o tanto que a delicadeza pode ser investida pela apreensão da mítica da sobrevivência. Jean, no último plano do filme, escreverá a história do olhar desviante, da capacidade de interpretar, talvez, um mundo que conhece apenas na urgência 
de suas fronteiras últimas. Olimite desse imaginário, que é sutil ao descobrir-se a si mesmo, como artefato e como enganação, que se descontrói, paulatinamente, porque todo o poder visual da identidade precisa ser ordinariamente desfeita de seus lugares de evocação conhecidos: a cena da intimidade derrubada dos corpos do rapaz e da empregada, no quarto dela, nos espaços da favela, são a permeabilidade real de um tempo que precisa ser melhor e mais amplamente conhecido que a tentativa de ocultá-lo nos conjuntos tradicionais de encarceramento (o tempo omisso da Casa Grande).

Jean, a partir de então, descobre-se livre da indústria dos muros, das prisões dos preconceitos, da força velada da melancolia e da esterilidade de um mundo ausente. Quando a personagem briga com o pai, saltando o muro da Casa Grande e disparando o alarme da residência, os processos da identidade já estão fora do alcance do universo da metáfora da paisagem (acolhedora, afetiva, transbordante). Sentir-se estrangeiro no âmbito comum passa a ser uma reminiscência da incapacidade em conhecer que todos os anos, desde o nascimento, foram a construção da inverossimilhança: o sujeito da cena passa a perceber-se como um ser opaco, sem peso na experiência do mundo, incapaz de aprender sem o auxílio - e ele é todo justo, urgentemente necessário - dos que são os mais descartados.

Nesse sentido, a condução do filme passa para a peregrinação da afetividade longe das categorias sociais, quando Jean é impulsado para os bastidores cotidianos da busca sobre os outros muros, que ele entende muito mais abertos, muito mais fáceis, da periferia carioca. O filme lê o contraste, nesse aspecto, pela metamorfose da descoberta, não obstante, sem desconcertos; o rapaz frequenta um baile noturno na favela e, em desespero silencioso, pede auxílio para as figuras - não importam os lugares - mais estáveis. A cozinheira, o motorista e a amante-confidente serão seguranças trilhadas com a desculpa para o primeiro, e real abrir dos olhos: o afastamento da Casa Grande, com coragem, em uma perspectiva que pode ser definida pelo sentido estrito da descoberta com olhos, posse do mundo dos sujeitos realizados por suas capacidades associativas livres, por suas experiências comuns e suas trocas ordinárias.

Mesmo que as designações sociais impeçam o trânsito atento entre as espacialidades comuns e incomuns dos mundos atrelados, Jean precisará, como a composição do filme investe, perceber-se no gesto crítico de não ter, e essa é a maior mudança nas fraturas da história narrada pelo filme, vergonha de assumir a identidade profanada. Todos os questionamentos virão depois, não obstante, a partir do acolhimento e do afeto, da descoberta da sexualidade e, talvez, de um olhar que precise conhecer a história da educação 
sentimental dessa alteridade negativa, omissa, constituída de forças marginais e representações políticas inexistentes. A perspectiva de retraimento e primeira negação de um mundo, que lhe nega o estado de força quando é criticado pela imagem como 'garoto privilegiado', portanto, impõe a necessidade de, para obter o amor, para conseguir a relação, ser necessariamente mais consciente das tensões entre os mundos diametralmente concebidos, em extensão e compartilhamento ${ }^{3}$.

Já em Que Horas Ela Volta (Anna Muylaert, 2015), o filme é composto, nesse aspecto, por um ordenamento similar que explora a tensão das relações entre patrões e empregados, sendo mais livre (e talvez menos potente) em pensar o jogo entrelaçado de dominação e invisibilidade concebidas pelo ensaio sobre um cotidiano de domínios de esperas (da pratica da dependência e da transmissão da objetificação, diversa, diferenciada, para corpos comuns e pessoas laboralizadas ${ }^{4}$ ). Aqui, também, é a chegada de uma jovem (Jéssica, Camila Márdila) que irá desestabilizar o laconismo das relações - revestidas por cortesias e figurações sem conhecimentos, sem escutas reais -, transformando a dinâmica distributiva das espacialidades da casa: os quartos dos patrões com varandas amplas, as janelas com grade que dão a pátios e divisores antes de chegarem ao jardim, da empregada.

Que Horas Ela Volta abre com a imagem de uma piscina em uma casa de classe média alta, no Rio de Janeiro, e apresenta os personagens de Val (Regina Casé, empregada doméstica da família há mais de dez anos), Bárbara (Karine Teles, patroa), José Carlos (Lourenço Mutarelli, patrão), Fabinho (Michel Joelsas, filho do casal). O filme nucleariza a condição da dependência nos detalhes das relações entendidas em seus universos de forças dominantes comuns, estabelecidos nos lugares essencializados como 'consciência' das posições: Val, a pessoa que deixou a filha no interior de Pernambuco para ser empregada doméstica de uma família de classe média alta em São Paulo, recebe a notícia de que a filha que não vê há vários anos virá a São Paulo tentar o vestibular em arquitetura. Jéssica fere a distribuição sub-reptícia dos imaginários dominados por linguagens de tolerâncias passivas (nunca há engajamento, nunca há real avanço sobre os dramas encenados, sobrevividos à força da anulação condicional) e questiona os lugares-comuns dos pertencimentos e os espaços ociosos: o quarto de convidados que não é usado e que é muito melhor que o lugar

\footnotetext{
${ }^{3}$ A linha demarcatória que certa alegoria das representações sociais pode impor na temática fílmica não é, no caso de Casa Grande, desenvolvida sem que a perspectiva psicológica dos personagens em suas profundidades relacionais sejam também observadas. A emancipação dos corpos é possível porque a decadência é um estado de perpetuidade dos mundos que não aceitam serem desestabilizados, mas sim seus indivíduos (quando o querem).

${ }^{4}$ Onde a única força de expressão (não há família, não há tempos, não há indivíduo), é a força (braçal) do trabalho doméstico.
} 
abafado que Val dorme e que irá dividir com a filha, colchão no chão, ventilador insuficiente.

Desde o conjunto de situações reescritas para pensar o plano das circulações dos corpos - a suspensão relativa dos mesmos - a máquina de indiferenças vestidas de diferenças sutis age onde tudo é revelado por sua grafia oculta, sempre ociosa, determinada pelo desequilíbrio e pela paternalização intoxicante: as relações de dominação são carregadas de pseudo-interesse, as ideias de emancipação não são descobertas das suas impossibilidades, os lugares são mantidos pela impermeabilização e o acesso restrito e a temporalidade das ocupações. O filme estabelece, crescentemente, atribuindo a personagem de Jéssica uma vontade de questionamento e reformulação das geografias de poder e seus intra-muros caseiros, as assimetrias mudas, indivizíveis, que são adensadas pela formalização dos desequilíbrios, das decadências das posições e do sem sentido das hieraquias, vistas pela mediocridade imediata ao mais mínimo movimento de relativização (custodiado pela falta de força em prolongar, mesmo admitindo os privilégios, as reconstruções necessárias para solver o dilema das assimetrias, como nas trocas verbais e nas confissões sozinhas entre Cláudio, o patrão e Jéssica).

A incapacidade em promover rupturas longas, nesse sentido, caminha para a disseminação de uma infinidade de espelhos, mantidos reversos e administrados pelo ocultamento da sensibidade real, potências de um falso que parece sempre vencer a autocrítica da imagem maior. Isto é, o fato do acobertamento e da impunidade dos ritmos, de seus rituais emudecidos, da servidão dos estados paralisantes serem sempre mais decompostos. Não há ação igualitária (mesmo braçal), por parte dos patrões, porque a verdadeira lei é concebida como um disfarce, uma alteridade que não existe como partilha e sim como aniquilação, desenhada na incapacidade de perceber que o que define as fronteiras não é a fala, não é o cortejamento (não é o afeto ressentido e exigente), mas a historicização (nula, anestesiada quando minimamente assistida) da auto-imagem, que é mantida sempre em segredo, em suas fissuras, em seus acordos tácitos (que vencem qualquer possibilidade de permeabilização dos preconceitos, medos íntimos e estranhamentos recíprocos) $)^{5}$.

O estranhamento, nesse sentido, não é uma variante da insuficiência do afeto (para redesenhar fronteiras). O estranhamento é uma pele que se entende mensageira de uma proteção da imagem, em todo e qualquer caso, vista como servidão posicional. A

${ }^{5}$ Como as qualidades secretas de um patrão artista sufocado que jamais saiu ao mundo, preferindo pré-existir na mediocridade. 
incapacidade em ler as subjetivações desde uma escuta não programada, aliada a falta de uma crítica frequente a toda a ordem pré-concebida, indisposta, dos afetos, propulsam a visão de possessão física antecedida pela possessão conceitual das distancias desses dois mundos, domínios de artefatização sempre incompleta ${ }^{6}$.

Ao tentar (des)glosar assimetrias, nesse âmbito, a diferença, que está na capacidade de emancipar-se, regressa à recusa dos espaços intersticiais, negados porque a visão pessimista (os outros não tem sonhos, os outros não tem vida antes e depois) prevalece sobre a imagem da integração. Nesse sentido, há um convívio multiculturalista, apenas admitido a partir de indivisibilidades e sustentações caracterizadas por simbolizações diferentes. A anomia dos discursos, que sempre são de outrem, alimentam-se desse outro que não consegue sobreviver dentro de um próprio, propulsando assim os projetos de possessão ritual e a possibilidade, convencional, alegórica apenas, da tentativa, se ela existisse, de compreender esse outro.

Não há nenhuma vontade, portanto, de produzir diferenciações e estranhamentos reais, derivados de um interesse etnográfico e (des)representacional: a necessidade de assegurar as posições mantém uma mesma metáfora assistida pela gravitação ao redor de um self possessivo (Clifford, 1999) e sem experiência estésica (sem, portanto, devires ou linhas de fuga).

Mas o filme de Muylaert também preconiza essa indivisibilidade da enunciação, ao lidar com os pequenos desconfortos, impalpáveis à primeira vista, na imagem das pessoas concebidas como normalidade social: as gigantes assimetrias são espaços de tensão que revelam um mundo entre desconfortos sub-reptícios, entre lugares desenhados no plano social como naturalizações reais de um eterno adiamento (os corpos não precisam do plano dos olhos, porque são lidos como objetos). Desses sujeitos comuns, dessas significâncias da imagem, o filme desenvolve-se na imbricação dos espaços extra-campo, das negativas dos registros, das perdas de autonomia que Val vai inevitavelmente evidenciando, com a chegada da filha a São Paulo.

Nessa irrupção, os lugares do distanciamento podem então serem mais diretamente observados: há negação como tendência de assumir, para os dois lados, a história de vida dependente do apagamento do passado terá que ser toda revista. Val será obrigada a enfrentar a voragem desses adiamentos, desde os recortes menores (nunca ter comprado uma casa para si) ao sentido completo da anulação individual (a experiência da auto-cárcere

\footnotetext{
${ }^{6}$ James Clifford (1999) comenta sobre esse paradigma ao pensar as relações entre concepção e recepção artística das produções culturais, entendidas assimetricamente, sobrevividas pela via da autoria para alguns e da cultura para outros.
} 
como proteção a um mundo exterior, o pacto de servilismo pela completude da transmissão afetiva com o filho da patroa, Fabinho).

A construção paradigmática entre mãe e filha, desse jeito, será uma busca pela perfuração da história, pela necessidade de irreprodução de seus preconceitos, pela tomada de consciência daquilo que revela mais: há muita proximidade (de corpos, de faltas, de transferências) nas relações entre Val e Fabinho, mas que é ausente entre Val e Jéssica. A diferença estará, portanto, sempre nos pequenos desconfortos, utilizados como constrangimentos que são deixados de lado, sempre menores que as outras dominações, naturalizadas: "isso aí não é para o seu bico", criva Val, para a filha que, como um ensaio do novo, não vê as distâncias porque não as concebe como verdadeiras.

Nesse sentido, o filme estabelece toda a mise-en-scène através da exposição naturalizada - das falas das personagens que ditam suas sentenças como se a alteridade nunca se reproduzisse em uma condição aberta, renovada, possível de ser apreendida pela interpretação do desconforto. Por isso, a ignomínia vestida de rotinização impede que os corpos sejam vistos como condições de um processo aberto, disponível pela realização dos seus desencontros, mas, também, das suas sinergias negadas.

O outro é sempre um outro que precisa vir de fora, que desfamiliariza o próprio, e que, em um estado de tensão, como na relação mãe e filha, acaba revelando o esforço em negar o trânsito, por parte de Val, e ver a insuficiência (de toda mudança) como fundamental. Cruzar a superfície dessa determinação é sempre o mais difícil na primeira descrição da intensidade com que os discursos servis são tensionados: quando Jéssica começa a questionar os lugares, seus corpos posicionais, suas inseparabilidades doentes, o que se vê é a muita proximidade sem adoção irrestrita, sem espaço para a independência dos sujeitos, sem o reconhecimento da dominação: “Tem coisas que a pessoa já nasce sabendo", diz Val em dado momento do filme, porque todas as situações deveriam ser programadas a uma utilidade maior, que mostra a interdependência exibida através de um rigor das posições não dialetais. O confronto é, nesse aspecto, uma característica das naturalizações das posições quando o sentido nunca é a reorganização dos estados individuais.

No fundo, as distâncias são vestidas com empoderamentos tão estéreis que nem a novidade nem o erotismo conseguem prevalecer: quando Zé Carlos se declara a Jéssica, e depois não segue em frente, a estabilidade anterior, covarde e medíocre, parece ser sempre mais forte que a tomada de decisão sobre qualquer mudança. 
O filme segue uma estrutura narrativa concebida pela continuidade temporal e pela organização dos espaços feitos a partir das falas que limitam os desejos, que irrompem, ao sempre serem de outros (que não podem, que não levam adiante). Quando as hierarquias são vestidas de circuitos de poder, as possibilidades de reversão dos mecanismos de orientação dos corpos impedem a durabilidade das inversões de papéis, assumidas como encenações perpétuas, adiamentos profundos, esquecimentos duradouros ${ }^{7}$.

Nesse sentido, os personagens parecem sobreviventes de alguma coisa que não tem acesso, ou que não sabem o que fazer com seu passado. $\mathrm{O}$ uso incerto dessa memória de alcance ilimitado mas de entendimento impossível, como diz Jeudy (1991), tem a ver com o sentimento dos corpos serem mudos, prisioneiros, 'escombros de si mesmos', vivendo vidas que não são as suas, deixando sempre a um porvir as mudanças que poderiam ser admitidas no momento. Sujeitos sempre em adiamento. Resignados a habitar lugares - incômodos, disponíveis e, no entanto, impedidos - que revelam os usos de vergonhas comuns. Seres em constrangimentos, portanto, que são dissimulados e desfeitos por afetos falsos, ou por pequenas cordialidades que são ordens de um comum, habitado pela resignação da espera que nunca chegará: a fonte de um mundo estrangeiro que levará a mais adiamentos, a mais negações interiores, aos olhos que não se cruzam e nunca se detém (para enxergar as abominações).

Os tensionamentos resultantes da dinâmica da co-dependência serão destapados ao longo do filme, em sua duração final. As ansiedades crescidas quando Val expulsa Jéssica da casa dos patrões, em um exercício de ordem que investe sobre a possibilidade da abertura, e colide com o choro que não vem, com a preocupação mecânica com as vidas tão opostas (Fabinho tendo acompanhamento e aconchego, Jéssica, na noite anterior ao vestibular, sendo expulsa da casa fictícia da mãe).

A chuva que recebe corajosamente a filha e que molha a mãe é, portanto, uma chuva que vem de fora como um chorar que nunca permite a condição maior do desencadeamento da mudança em um caminho de investida da oportunidade do amparo (Val não corre atrás da filha). É, não obstante, a fotografia do bebê de Jéssica que desestabiliza o mais profundo, o mais errático. A força do afeto somente pode ser substituída, parece ser, por um afeto mais profundo, entrega completa de si, memória que permite, pela fotografia, soldar um passado constrangido de séries de abandonos.

\footnotetext{
${ }^{7}$ Há sempre a sensação, ao longo do filme, que os deslocamentos são sufocados por esterilidades viciosas da condição recíproca da dependência: o sujeito nunca está limitado pelo terreno das ordens, mas pela resiliência com que elas reorganizam a percepção de ruptura e pelo efeito de descontinuidade que há entre as encenações comuns e os encadeamentos novos.
} 
Nesse sentido, os minutos finais do filme encorajam a justificativa dessa realização de um imaginário (a remissão do passado pela possibilidade, não mais remota, de regresso ao laço original). Quando Val recebe a notícia de que Jéssica "fez 68 pontos no vestibular", a singularidade da relação parece incidir sobre o peso da imagem materna; os corpos, estranhamente, na casa em que está, estão desalinhados (a patroa, Bárbara, não abraça Val) e a mudez toma conta da casa, que será solitária e coberta de esvaziamentos: Val pedirá demissão, Fabinho irá para a Austrália, pois não passou no vestibular, e o casal terá que conter sozinho toda a reorganização da casa ${ }^{8}$.

O ensaio sobre a dissecação do mundo (das ausências, das rupturas silenciosas ocupadas por projetos de igualdade falsos), será percebido com o consolo da mensagem de que a espera pode ser feita, de outra forma, desde a reorganização do centro da afetividade para o sistema de parentesco. Val pede demissão e justifica-se com a patroa, que quer aumentar o salário: “Não, não é isso. É coisa minha...”.

Há, portanto, permissão para o sonho. Há, também, substância sobre o arrependimento; a correção do sistema de privilégios e o entendimento de que a relação somente pode ser proveniente de uma nova condição da imagem: a casa que sempre fora grade e a piscina que sempre fora poço será deixada para trás. A partilha, porém, terá suas consequências quando Fabinho vai embora, porque parte, também, a potencialidade da ocupação, da ciclotimia de abandonos que impôs, ao outro, ao tão próximo porque veio de tantas distâncias, a história da perda da própria história, no migrante, na Val que chegou de muito longe, talvez com fuga, provavelmente substituindo os sonhos antes de conseguir conhecê-los. Suas ficâncias mudas, seus desalinhos, suas coisas pesadas que, de repente, chegam na memória. (e se instalam para nunca mais sair.).

É certo que o filme termina com rosto pronto para o melodrama. Mas há pouco desse lugar de expectativas recém ocupadas pela organização da ausência, pela percepção dos ciclos de fuga. Não mais como a história das humilhações tergiversadas em afetos falsos, mas a consciência do devir, do preenchimento de uma individuação sempre feita pela abertura, pelo cuidado outro (Val cuidará do neto, Jorge, a quem ama com acolhimento, irrestrito, sem conhecer ainda).

Quando o laço é desfeito, como escreve Kehl (2011), a profunda fé no objeto de amor parte como a experiência também parte; a estrutura do pertencimento poderá ser, então, renovada pela condição, a ser aprendida, do desejo de adotar um outro.

\footnotetext{
${ }^{8} \mathrm{O}$ filme é realizado em uma mise-en-scène que se articula pela positividade, talvez especialmente mais rasa nos minutos finais, quando o uso do esteretópico avança sobre o domínio narrativo: a música extra-diegética entra pela primeira vez na composição final, quando Val entra sozinha na piscina e experimenta a sensação de liberdade.
} 


\section{Considerações Finais}

O outro lado do exercício da identidade, em Casa Grande e Que Horas Ela Volta é a incompreensão, nesse caso, da violência de negar ser habitado por afetos (afetos outros, amparados apenas por suas faltas). Observa-se que a precariedade laboral é apenas uma das facetas da dissimulação do imaginário da relação, pois a normalidade parecer ser, nos dois filmes, estabelecida a partir de um permanente estado de tensão sub-reptício que demarca a fronteira entre o eu e o outro, sobretudo, na incapacidade em promover sentidos sociais para uma relativização duradoura e crítica da questão da posição das presenças.

Quando a personagem de Jéssica (Camila Márdila) invade a cena e desestabiliza os finos sentidos e as relações de dominação e servidão entre patrões (Bárbara e José Carlos) e empregada (Val) em Que Horas Ela Volta, os universos de emulação fraternal entre os corpos pede remissão: mas a imagem da metáfora da fraternidade vai embora apenas quando um afeto é suspendido; no centro da narrativa, a partida de um objeto de cuidado e amor (Fabinho) recoloca a dimensão afetiva em seu lugar de origem.

O filme, nesse aspecto, possui uma revisão da pragmática do abandono e da transferência por ausências: o consolo (cuidar de um filho que não é seu) é o outro lado da relação de uma falta como partida; a narrativa de Que Horas ela Volta descansa, portanto, na imagem, poderosa, do sofrimento das relações livres (Fabinho) e condicionadas pela origem social (Jéssica). Se, como diz Viveiros de Castro (2005, p. 157), "relacionar é assemelhar, unificar, identificar", o filme produz a consciência da relação, por parte da personagem principal (Val) apenas no momento final, quando uma partida (Fabinho, rumo a Austrália) e o entendimento de uma chegada definitiva (Jéssica, entrada na universidade, e Val, que descobre ser avó) dissecam o universo das metáforas fraternais (a dominação por afetos).

Os constrangimentos dissimulados entre as relações patrões-empregados, no filme de Muylaert, escondem identidades sub-reptícias, compreendidas no modelo de relações sociais que não observam seus estados de codependência: o fibroso ordenamento das individualidades redime a falta que implica em uma desidentificação parcial do pertencimento de origem. A afeição pela criança que não é sua, mas que é acolhida como identificação irrestrita é a base do sentido da permanência em outro espaço (solitário, 
indivisível, indisponível) que entrelaça as situações carinhosas com as diferenças (sempre sutis, sempre mais duras) de marcação dos corpos e seus rígidos lugares de inscrição (que, de forma ambivalente, parecem distantes dos desejos dos indivíduos).

As distancias sociais, desse modo, parecem nunca serem superadas pela necessidade, maior, de desenvolverem suas personas imaginárias. O afeto é, dessa forma, a causa e o desconhecimento da dominação, porque impede o reconhecimento da medida exata do que é o ato contínuo da despersonalização: anulam-se corpos pois há um acúmulo pulsional, personagens que precisam dos outros para (continuar) fazendo viver as metáforas da fraternidade e harmonia presencial. Sob o peso dessas locuções (viver na direção de sujeitos que não praticam objetificações) transforma a lógica dos imaginários mais reais que o âmbito das relações, distantes das suas especificidades e de seus lugares históricos de rejeição e abandono\%.

Philippe Lacoue-Labarthe e Jean-Luc Nancy (2013) expõem essa questão ao pensar sobre as dificuldades entre o trânsito da identidade (socius), como um lugar de apoio a força do desamparo e a possibilidade sempre aberta das identificações. A angústia individualista é concebida, nos dois filmes, por sistemas de relações que provavelmente duram mais que os corpos que os tornam presentes: há, por exemplo, como no personagem do patrão em Que Horas ela Volta (José Carlos) uma vontade relativista, um desespero da transformação (o personagem mostra ambiguidade em relação à Jéssica) e reproduz, em um trânsito similar (em uma identificação aberta e muito próxima ao que Val faz como Fabinho), o que é transmitido (a herança familiar, os lugares de empoderamento essencializados), apenas idealmente preparado para ver o que se observaria, de maneira racional, a posição 'confortável' no sistema de dependência ${ }^{10}$. Não obstante, quando tensionada, quando descoberta, as relações subvertidas e suas frequências livres, dispostas a estarem mais longe do regime de fronteirizações (a Casa Grande indo à senzala e a Senzala engolindo a grande casa), são solvidas pela violência como instrução de um socius sintomático: a potência (da relação) é sempre mais proibitiva para a intimidade ser salvaguardada; as vontades (de emancipação, de trocas mútuas), perduram apenas o tanto que são negadas pela externalização da diferença, ipsis litteris, porque a exposição de que a diferença é do domínio das percepções (e não da essencialidade) acaba transportando a mesma ao universo de uma

\footnotetext{
${ }^{9}$ A lógica dos imaginários predispostos a serem encarnados como reais é, em certa medida, a mesma lógica que expõe Sibilia (2008) dos "sobjetos", sujeitos (outros) investidos de funcionalidade e objetos (materialidades, condições) imantados de pessoalidades.

${ }^{10}$ Ele diz, em determinado momento da diegése, abertamente, junto a Jéssica: "Não tenho dinheiro. Herdei tudo isso".
} 
única operação: a diferença não é vista como uma possibilidade além do compartilhamento, porque as relações, por serem premidas por uma identidade absoluta, acabam sendo concordantes com uma lógica da dependência ${ }^{11}$.

A sensibilidade como uma troca expressiva e realizável é dissolvida, dessa maneira, pela força da identidade: as relações não podem ser seduzidas por afetos comuns, por presenças reconhecidas apenas em suas faltas (e não apenas físicas), mas se tornam assimetricamente desfeitas (e a lógica principal é a tentativa de reequilíbrio dessas forças) pela durabilidade das negações ${ }^{12}$.

No filme de Felipe Barbosa, o centro da narrativa, por sua vez, é direcionado pelos olhos do rapaz, que percebe os vínculos faltantes e o âmbito das diferenças, como expõe Dunker (2015), além dos muros das construções do parentesco. As discursividades mudas, nesse caso, predicadas pelas partilhas parentais, são suspeitas, aos olhos do rapaz, porque a imagem do estranhamento não é necessariamente um obstáculo para o conhecimento social. Ao contrário, as diferenças carregam essa ideia da estranheza como o movimento do fascínio da descoberta (o rapaz se interessa por uma moça de classe social diferente, sentese a vontade na comunicação com a empregada da família, desenvolve labilidade direta com os demais empregados).

A perspectiva de conhecer uma realidade que é amplamente diversa do mundo de referência, portanto, surge no filme como uma vontade de percorrer o caminho do afeto pela liberdade de admissão (des)essencializada. Como diz Viveiros de Castro (2005, p.160), “a diferença é, portanto, a condição da significação, e não obstáculo". A diferença entre patrões e empregados, em Casa Grande não é, nesse sentido, um disfarce da relação, mas o estado de omissão que as 'naturezas' distantes parecem ser concebidas, dentro de suas ontologias (mudas) constituídas pelas perspectivas não resolvidas pela exposição de suas historicidades (de seus mundos originais, sobreviventes). A máquina da internalização dos lugares, seus posicionamentos e suas concepções (a noção de pessoa) é dissolvida parcialmente, no filme de Felipe Barbosa, pelo personagem de Jean, capaz de desinteressarse da continuidade natural dos mundos unívocos das relações sensíveis (quando o rapaz se

\footnotetext{
${ }^{11}$ Que é, na esfera das lógicas sociais, uma codependência negativa, 'potências do falso' (Deleuze, 1990) que representa a si mesmo em uma relação objetificada por força ou afeto (noção de fetiche).

${ }^{12}$ Os dez anos sem ver a filha, por parte de Val em Que Horas Ela Volta, nesse sentido, são tão crus como a negação do abraço entre mãe e filho, para além do desconhecimento, entre Bárbara e Fabinho; as relações entre consanguíneos, paradigmaticamente, sofrem da (in)fiabilidade das dependências recíprocas. A tradução dessa ideia é que o paradigma da cordialidade, no fundo, tem mais força que as relações comuns, pois a natureza da afetividade parece se dirigir por uma condição de desvestimentolinvestimento mais livre, menos programática nas identificações que 'saltam' o sistema de parentesco e relações.
} 
sente só, desce ao quarto da empregada, que é a partilha doce, segura, e ao mesmo tempo disposta ao compartilhamento).

Nesse caso, os afetos são sociabilidades de relação concebidos como enclausuramentos que não admitem, para a ordem de direções diversas, equívocos na interpretação: como performance, como rituais de cortesia e afirmação eles não podem ser desentendidos das fabricações dos poderes, da cultura específica da ampla plasticidade simbólica seguida de um mínimo de capacidade de metamorfose (anulando qualquer possibilidade de mudança social).

O (des)afeto, seguindo esse prisma, é um constrangimento porque expõe a natureza do sistema social das suas falhas incontornáveis: a incapacidade de distender o sistema de relação através de suas bordas, desde suas periferias (o quarto da empregada, as festas dos bairros afastados, a contemplação da cidade do universo da favela, etc.). $\mathrm{O}$ acúmulo de tensão pulsional, dessa maneira, que sobrevive no risco de se imaginar o que aconteceria se uma das partes, se uma das posições fossem permanentemente questionadas (e, por isso, como no filme de Kleber Mendonça Filho, O Som ao Redor, as relações são como barris de pólvora) é, de todas formas, um acúmulo que tem sua solução pela intensificação do drama social (Dawsey, 2005) que gera, no desfecho, geralmente um abandono, ou uma solução violenta.

A imagem da sociabilidade conciliável, tanto em Que Horas Ela Volta como Casa Grande remete a perspectiva da fascinação pelo desagravo em um processo que, como reflete Kehl (2011), tem a ver com as sensibilidades premidas pela vontade de emancipação, mas que, na construção social do habitar na realidade cotidiana brasileira, acabam sendo vistas dentro do imaginário da experiência clandestina. A execussão da alteridade em Que Horas Ela Volta (Anna Muylaert, 2015) e Casa Grande (Felipe Barbosa, 2014) é estabelecida em seus desencontros (Fischer, 2009), pequenos desencantamentos (Val ao longo do filme), que mostram que a ruptura, nesses casos, é mais difícil porque significa um o reconhecimento de uma cisão irreparável: crise, intesificação da crise, percepção da despersonalização sintomática (Que Horas Ela Volta) e sentimento de abandono dentro de um sistema feito para proteger, mas que impede, filtra, seletiviza as relações (Casa Grande).

A precocidade dos laços e a clandestinidade dos apegos, feitos livremente na solidão da casa (Muylaert) e na noturnidade insolvente (Barbosa), apresentam a dissecação de uma sociedade carregada de irrupções e descompassos entre a admissão da alteridade pela via do 'pessimismo sentimental' e pela clausura dos reconhecimentos (os mais difíceis) que mostram, não obstante, o quão mudos, parciais, transitórios, são os ensaios sobre a 
iniquidade das relações quando desfeitas de seus nomes (das durações de seus motivos, dos usos, para os dois lados, dos processos de agenciamento). Os paradigmas sobre as sentidas (i)mobilidades clássicas da realidade social brasileira desde o comum da repetição - a sobrevivência do sistema de diferenciação sem diferenças, por um espelhamento omisso, baseado em uma ideia de sociabilidade frontal e sem preconceitos - são dissolvidos, na consecussão da crise do imaginário, pela anacronia da metáfora do relacionamento 'cordial', 'assentido' e 'participativo'.

Os dois filmes tensionam, como pragmática discursiva, a ordem pulsional da ciclotimia das relações patrões-empregados, estabelecidas pela noção culturalmente situada de que, desde o universo das pessoas, seus lugares, suas formas de procedência (Matta, 1997), os processos de formação são sempre mais determinantes que as possibilidades de 'equivocá-lo'.

O fundamento principal, nesse caso, segue sendo a dificuldade de obter sentido crítico para a relação vista desde sua procedência infame, pois em Que Horas Ela Volta (Anna Muylaert, 2015) e Casa Grande (Felipe Barbosa, 2014) as potências do imaginário são sempre mais sobreviventes que a vontade de 'desacumulação' da carga de pertencimentos essencializados. A via da codependência, estabelecida na afetividade sem disposição ao enfrentamento das disparidades das diferenças (substituídas por semelhanças irreais, deduzidas do tratamento cortês que esconde um acúmulo de pequenas violências cotidianas) torna, portanto, o reconhecimento laboral mais impreciso e também a falta de atenção ao princípio de dominação se esquece do mais básico: as relações são de dominação porque são lidas como necessidade.

Como se, nos dois filmes, nesses dois núcleos da identidade brasileira determinada pela quantidade de imbricações entre pares subjulgados (e ímpares díspares) a ordem dos afetos fosse consumida pelas suas disparidades insolventes, pelo fracasso da (des)identificação real, feita para manter o equívoco (da identidade) uma maneira de não esconder o pouco otimismo ou o pouco interesse num outro que se frequenta, isso sim, sempre amplamente, sempre na linha do abuso e da perspectiva da relativização dos gostos (horas noturnas extra-laborais validadas por um pedaço de doce) mas que, nos termos das relações, jamais invertem a questão que acaba sendo, ao fim e ao cabo, a mais determinante: como diz o antropólogo, "... o oposto da diferença não é a identidade, mas a indiferença" (Viveiros de Castro, 2005: 158).

No caso de Que Horas Ela Volta (Anna Muylaert, 2015) e Casa Grande (Felipe Barbosa, 2014), os afetos são instruídos para suspenderem ou anularem, momentanemente, a origem 
da dominação. Da mesma forma, o sistema de constrangimentos é desenvolvido como falta entre as diferenças da ordem da incomensurabilidade (negar os afetos, desestabilizá-los por sentimentos comuns, inscrevê-los como uma condição, possível ou não, mas sempre posterior à contratualidade correta), e o efeito de uma incomunicabilidade maior, feita pelo imperativo da proximidade (dos corpos, das suas caríciais) mas nunca de seus abandonos. As hierarquias dessas relações que, instigadas também por afetos mudos, não são violadas por suas regras de intolerância de partida (a Casa Grande não vai a Senzala para romper seus muros nem a Senzala se introduz na Casa Grande, como a personagem de Jéssica fez, para questionar seus labirintos).

É, justamente, na clandestinidade dos apegos, que sobrevivem as alteridades assimetrizadas (simetricamente entendidas, nesse caso, com o cegar de situações sociais tão díspares), que as (i)mobilidades clássicas do sistema social brasileiro, conforme aponta (Santos, 2001), são perpetradas, no caso dos dois filmes, desenvolvendo a interpretação de que o desejo (ser um outro sem percebê-lo, ou sem perceber a si mesmo, o que de modo correlato é a mesma coisa) pode ser mais livre que desenvolver a prática da alteridade em um lugar de equívoco.

Analogamente, como reflete o antropólogo (Viveiros, 2005), significa dizer que nunca somos nem poderemos ser iguais, e que as distâncias, que os equívocos precisam reconhecer todas as lacunas antes de reconhecerem a si mesmos; porque, entre a Casa Grande e a Senzala, se canais de afetividade existem, eles precisam, sempre urgentemente, sair da clandestinidade.

"Discernir rupturas culturais e continuidades culturais, traçar linhas em torno de conjuntos de indivíduos que seguem uma forma de vida mais ou menos identificável... é bem mais fácil na teoria que na prática. [...] Quanto mais as coisas se juntam, mais ficam separadas."

(Geertz, 2001: 217) 
Teixeira, Rafael Tassi. Da Violência como Instrução ao (Des)afeto como Constrangimento: Acumulação Pulsional, Identidades Segmentadas e Clausuras do Comum em Casa Grande (Felipe Barbosa, 2014) e Que Horas Ela Volta (Anna Muylaert, 2015)

\section{Referências Bibliográficas}

CLIFFORD, James. Dilemas de la Cultura. Barcelona: Gedisa, 1999.

DA MATTA, Roberto. A Casa e a Rua: Espaço, Cidadania, Mulher e Morte no Brasil. Rio de Janeiro: Rocco: 1997.

DAWSEY, John. "O Teatro dos Boiás-Frias: Repensando a Antropologia da Performance”, Horizontes Antropológicos. Porto Alegre, ano 11, n. 24, jul \dez, 2005.

DELEUZE, Gilles. A Imagem-Tempo. São Paulo: Brasiliense, 1990.

DUNKER, Cristian. Mal Estar, Sofrimento, Sintoma: Uma Psicopatologia do Brasil entre Muros. São Paulo: Boitempo, 2015.

KEHL, Maria Rita. Ressentimento. São Paulo: Casa do Psicólogo, 2011.

FISCHER, Sandra. Cotidianos no Cinema Brasileiro Contemporâneo: Imagens da Família, da Casa e da Rua. Porto Alegre: EditoraPlus.org, 2009.

GEERTZ, Clifford. Nova Luz Sobre a Antropologia. Rio de Janeiro: Zahar, 2001.

JEUDY, Henri Pierre. Memórias do Social. Rio de Janeiro: Forense Universitária, 1991.

LACOUE-LABARTHE, Philippe e NANCY, Jean-Luc. La Panique Politique. Paris: Christian Bourgeois Editeurs, 2013.

RANCIÉRE, Jacques. O Espectador Emancipado. São Paulo: Martins Fontes, 2015.

SIBILA, Paula. O Show do Eu: A Intimidade como Espetáculo. Rio de Janeiro: Nova Fronteira, 2008.

VIVEIROS DE CASTRO, Eduardo. "Equívocos da Identidade", IN: GONDAR, Jô e DOBEDEI, Vera (orgs.). Rio de Janeiro: ContraCapa, 2005. 